\title{
Population assessment of common storage pests in deiri date palm cultivar using spectrophotometric method
}

\author{
Masoud Latifian ${ }^{1} \cdot$ Bahar Rad $^{1}$
}

Received: 17 July 2020 / Accepted: 11 May 2021 / Published online: 15 May 2021

(c) The Author(s) 2021

\begin{abstract}
Opportune and accurate identification of Date pests during storage, is prerequisite for reducing pest damages and having a good export. The present study aimed to define a new sampling method for three main storage pests Oryzaephilus surinamensis (Linnaeus), Ephestia kuehniella (Zeller) and Plodia interpunctella (Hübner) in date Deiri Cultivar, by Spectrophotometer. The experiments were conducted in a completely randomized design with factorial arrangement in two levels. The first factor consisted of 4 levels including different stages in pests life cycle and the second factor had 10 levels including different densities of each development stage of insect species. First, the curve of changes in absorbance level in each life cycle stage was plotted against the wavelength changes and again it was repeated for each species. This curve enabled us to determine the absorption range of the device in different wavelengths. Our results showed that the maximum absorption wavelength for egg, larva, pupa and adult of $O$. surinamensis, in Deiri Cultivar was 1210, 1230, 1250, $1270 \mathrm{~nm}$, respectively. These values were 1320, 1340, 1380, $1390 \mathrm{~nm}$ for E. kuehniella and 1350, 1400, 1410, $1480 \mathrm{~nm}$ for P. interpunctella, respectively. The lowest sample size (each sample consisted of $110 \mathrm{~g}$ of date fruits) for an accurate estimation of theegg, larva, pupa and adult of $O$. surinamensis were 1,2,2, 2, respectively. These values were 1, 1, 3, 3 samples for E. kuehniella and 1,2,2, 2 samples for $P$. interpunctella, respectively. The Relative Variation values for the four development stages of $O$. surinamensis were 1.39, 2.41, 2.91 and 3.12, respectively. These values were 1.59, 1.63, 4.62 and 4.34 for E. kuehniella and 1.78. 3.24, 2.62 and 2.24 for $P$. interpunctella, respectively. The accuracy level of samplings was lower than 10 in all the cases. The Relative net precision values for three studied pests in all life cycle stages were 35.95, 20.73, 17.19, 16.06 for $O$. surinamensis; 31.32, 30.69, 10.82, 11.53 for E. kuehniella and 28.15, 15.42, 19.05, 22.27 for P. interpunctella, respectively. Therefore, we can conclude that the spectrophotometer can detect the hidden life cycle stages of studied pests in Deiri cultivar during storage and reduce the cost of sampling.
\end{abstract}

Keywords Date $\cdot$ Storage pests $\cdot$ Sampling $\cdot$ Spectrophotometer

\section{Introduction}

Oryzaephilus surinamensis L., Ephestia kuehniella (Zeller) and Plodia interpunctella (Hübner) are the most important stored product pests in the world which damage dates by reducing quality and quantity of dry and semidry date fruits (Al-Dosari et al. 2002; Mallah et al. 2016). The saw-toothed grain beetle (O. surinamensis) is a

Masoud Latifian

masoud_latifian@yahoo.com

1 Agricultural Research, Education and Extension Organization (AREEO), Horticulture Science Research Institute, Date Palm and Tropical Fruits Research Center, Ahwaz, Iran slender dark brown beetle $2.4-3 \mathrm{~mm}$ in length, with a flattened body, and six saw-toothed projections on each side of the prothorax. The larva is elongate yellowish-white with a brown head, has numerous setae (hairs) and three pairs of legs. The long forewings of E. kuehniella is rather rounded tips. Forewing pale-grey or brownish-grey. Head, thorax and abdomen grey. Its egge is oval, sometimes with a slight projection at one end, greyish-white. Mean size $0.57 \times 0.30 \mathrm{~mm}$. The head capsule on newly hatched larvae will be less than the width of eggs. Pupa is yellowish or reddish-brown; dorsal surface of head and prothorax rough, cremaster rounded, with eight hooked setae. Adults of $P$. interpunctella are about $12.7 \mathrm{~mm}$ long with a wing span of about 16 to $20 \mathrm{~mm}$. The forewings of this moth are reddish brown with a copper sheen on the outer two thirds 
and gray on the inner third. The head and thorax of the moth appears gray and the posterior brown, with a coppery sheen. Eggs appear grayish white and range in length from 0.3 to $0.5 \mathrm{~mm}$. The color of larvae is usually off-white, but has been observed to be pink, brown or almost greenish, depending on the food source. The mature larvae are about $1.27 \mathrm{~cm}$ in length. The pupae are 6 to $11 \mathrm{~mm}$ and are pale brown in color (Gorham 1991).

Detection of storage pests is very important in the early infection. Spectroscopy is one of the methods used in recent decades to detect storage pests in the early infection accurately (Wilkin et al. 1986). The field work of sampling should be done after selecting the sampling method, measuring instrument and determining the maximum absorption wavelength. In addition, the sampling must be repeated, so that the estimates can be reliable and validstatistically. The sampling accuracy is determined by the sample sizes, which is needed for evaluation (Wilkin and Fleurat-Lessard 1991; Throne et al. 2003).The sampling plan includesthe selection style of a sample from the community and the evaluation of the pest population density. Then, a specific technique is designed to assess the community parameters with high reliability, by using the obtained data in the sampling method (Morrison et al. 2019).

Infrared spectroscopy is used to detect the amount of water, protein and oil in the food industry (Williams and Norris 2001). In this method, wavelengths between 700 to $2500 \mathrm{~nm}$ can be used. The vestigial organs of insects in the food stuffs are also detectable with Near Infrared spectrophotomey (NIRS). Hemolymph type, fats and chitin of insects can affect the suitable wavelength. Since chitin is also in the fungal tissue, this method is used to detect fungal infections in stored agriculture crops too. NIRS method has been used for detection of mites and various insect pests including Acarus siro (L.) Oryzaephilus surinamensis (L.), Sitophilus granarius (L.), Rhyzopertha dominica (Fabricius), Sitotroga cerealella (Olivier), Prostephanus truncates (Horn), Tribolium castaneum (Herbst), Sitophilus oryzae (L.), Drosophila melanogaster (Meigen), and Plodia interpunctella (Perez-Mendoza et al. 2003; Burks et al. 2000; Throne et al. 2003; Ridgway et al. 2001; Zayas and Flinn 1998; Chambers et al. 2001).

NIRS can detect different cuticular lipids of insect species. The compounds of the insect cuticle that can be identified are pigments, proteins, Catalase and oxalates (Williams and Norris 2001). There are many differences between the spectrophotometer wavelength absorption based on Melanin and Sclerotin quantity in the insect cuticle (Burks et al. 2000). Therefore, the energy level and wavelength absorbed will be different depending on the cuticle chemical composition and the population density of the different life cycle stages of each pest species in the stored agricultural products (Ridgway et al. 2001).
Also, the spectrophotometric technique has been used to differentiate between healthy and damaged organs in the plants. For example, this method has been used to detect sucker pest's injury in tomato by 500 to $1000 \mathrm{~nm}$ wavelength of beam spectrum (Lu et al. 2017). Likewise, it has been used to detect plant pathogens including Viruses, Viroids and Mycoplasmas (Huang et al. 2018; Jinendra et al. 2010; Mahlein 2016; Naidu et al. 2009; Sankaran et al. 2010).

In this study, different indicators such as suitable wave lengths for species identification and developmental stages, sample sizes needed to determine population density and assessment of sampling accuracy and resolution were done to explain the standards of spectrophotometric method and its calibration for detecting species and developmental stages of three important storage pests including $O$. surinamensis, Ephestia kuehniella (Zeller) and P. interpunctella in stored Date (Deiri cultivar).

\section{Material and methods}

\section{Insects breeding}

\section{Rearing saw-toothed beetle}

Different developmental stages of $O$. surinamensis were collected from the contaminated warehouses of Date fruits in Khuzestan Province of Iran and sent to the Entomology Laboratory of Date palm and Tropical Fruits Research Center. The insects were reared on the three cultivars of date including Sayer, Zahedi and Deiri, at temperature $27 \pm 5^{\circ} \mathrm{C}$ and a relative humidity $60 \pm 5 \%$ with $12 / 12 \mathrm{~h}$ of light/ dark in the growth chamber within plastic containers $(8.5 \times 7.5 \mathrm{~cm})$. A hole was made on the top of each container for ventilation which was covered with a mesh cloth (12 holes/cm2).

\section{Rearing of Indian meal moth and Mediterranean flour moth}

The flattened cap glass containers were used for reproduction of P. interpunctella and E. kuehniella in the laboratory. The container was heated to ensure that it was not infected. Every week the female insects were transferred to new glass containers for laying. First, a growth medium was prepared for growing this moth. For this purpose, $1.5 \mathrm{~kg}$ of wheat flour plus $0.5 \mathrm{~kg}$ of bran were mixed with a small amount of yeast. After mixing, one gram of moth eggs was poured on it and then covered with a clean cloth on a pan. After about 40 days, the first moths were observed and catching was begun. There were approximately 500 moths inside each container, covered with a fine mesh cloth on the top of each container. A funnel or cylindrical container was placed in a short distance from the bottom of the sheets until the moths laid their eggs from the lattice holes on the bottom of the 
container on the sheet. All three species were reared for ten generations before the experiments were performed.

\section{Preparing samples}

$110 \mathrm{gm}$ of Deiri cultivar fruits were sliced and weighed by a digital balance (with 0.001 graccuracy). The fruits were placed into an Erlene with 1-L capacity, containing a solution consisting of $\mathrm{Nacl}(20 \mathrm{gm}), \mathrm{NaOH}(30 \mathrm{ml})$ and $\mathrm{H}_{2} \mathrm{O}(40 \mathrm{ml})$. Erlene's content was boiled on the heater and passed through the filter after $10 \mathrm{~min}$. The insects in different life cycle stages including eggs, larva, pupa and adult with different densities $(5,10,15,20,25,30,35,40,45$ insects $)$ were separated. Then, $25 \mathrm{ml}$ of the extract from the solution, which contained insects in the special life cycle stage and in a specified density, was taken and homogenized in small beaker. Finally, the resulting suspensions were transferred to the test tubes by micropipette (Latifian et al. 2013; Latifian and Rad 2015).

\section{Determining the wavelength for identification of species and developmental stages}

The spectrophotometer used in this study was UV-Visible type (Varian Kerry 100 scan model). In order to set the spectrophotometer, the cuvette was filled by distilled water and inserted into spectrophotometer for reading zero of apparatus. Then the samples were prepared and test tubes containing the different pest densities were shaked for one minute before reading to uniformly mix the contents of the suspension. Then, one $\mathrm{ml}$ of the mixture and three $\mathrm{ml}$ of distilled water were poured into the cuvette by using a micropipette and placed in the spectrophotometer. At each step, the selected wavelengths were applied at $50 \mathrm{~nm}$ intervals, from 800 to $1900 \mathrm{~nm}$, and the absorptions data was recorded. All experiments were replicated three times (Latifian et al. 2013; Latifian and Rad 2015).

\section{Data analysis}

At first, the absorption curve for each life cycle stage ofthe insects were plotted according to applied wavelengths, by partial least squares regression. The absorption ranges of spectrophotometer were determined at different wavelengths by these curves. Despite the overlap possibility at the maximum absorption limit for different insects, themost suitable wavelength with the maximum absorption was determined for each species developmental stage. For this purpose, the quadratic relation curves were plotted between the absorptions as dependent factors and wavelengths as independent factors. The maximum point of these curves was equivalent to the wavelengths at which there was maximum absorptions for the tested insect developmental stages. For this purpose, the regression equations were driven by differentiating thee quations and estimating maximum absorptions by calculating absorptions under conditions whichthe derivative was equal to zero (Huang et al. 2018).

\section{Calibration models}

Different densities $(5,10,15,20,25,30,35,40,45$ and 50) of egg, larva, pupa and adult of $O$. surinamensis, E. kuehniella and $P$. interpunctella were separated. Three samples of each density were prepared and inserted into spectrophotometer. At each absorption reading step, data were saved after applying the selected wavelengths. All experiments were replicated three times for each density of the insects developmental stage (Dudhe et al. 2017).

\section{Data analysis}

The experiment was conducted in a completely randomized design with factorial arrangement in two levels. The first factor was different life cycle stages of the insects, including 4 levels (eggs, larva, pupa and adult) and the second factor was number of insects in each life cycle stage, including 10 levels $(5,10,15,20,25,30,35,40,45$ and 50). Experiments were conducted in three replications. The means were compared by Duncan's multiple range test at $5 \%$ level of significance.

After this stage, the relationship between the absorptions of each life cycle stage was investigated at different densities. Partial least squares regression analysis was used for this purpose. Based on the analysis, the calibration model was designed, using Excel software, based on linear regression model (Arbogast and Mankin 1999). The indices used in the data analysis were calculated by Eqs. 1-3 (Bowditch and Madden 1996):

Standard error $s \bar{x}=\frac{s}{\sqrt{n}}$

Relative Variation $R V=\frac{s \bar{x}}{\bar{x}} \times 100$

Relative net precision $R N P=100 /(R V \times C)$

In these equations, $\mathrm{S}, \mathrm{n}, \bar{x}, s \bar{x}$ and Care samples standard deviation, sample number, population mean, mean of variance and $\mathrm{C}$ sampling cost respectively. If the RNP and RV are less than 25 and 10 respectively, the sampling method is considered acceptable in the integrated pest management (Bowditch and Madden 1996).

\section{Results}

\section{The most suitable wavelength for detecting developmental stages}

The spectrophotometer absorptions at 25 densities $/ \mathrm{kg}$ were plotted based on wavelengths from 800 to1900 nm for the 
Fig. 1 Variation in the spectrophotometer absorption wavelength (at the range of 800-1900 nm) for different life cycle stages of $O$. surinamensis, E. kuehniella and P. interpunctellain Date (Deiri cultivar)
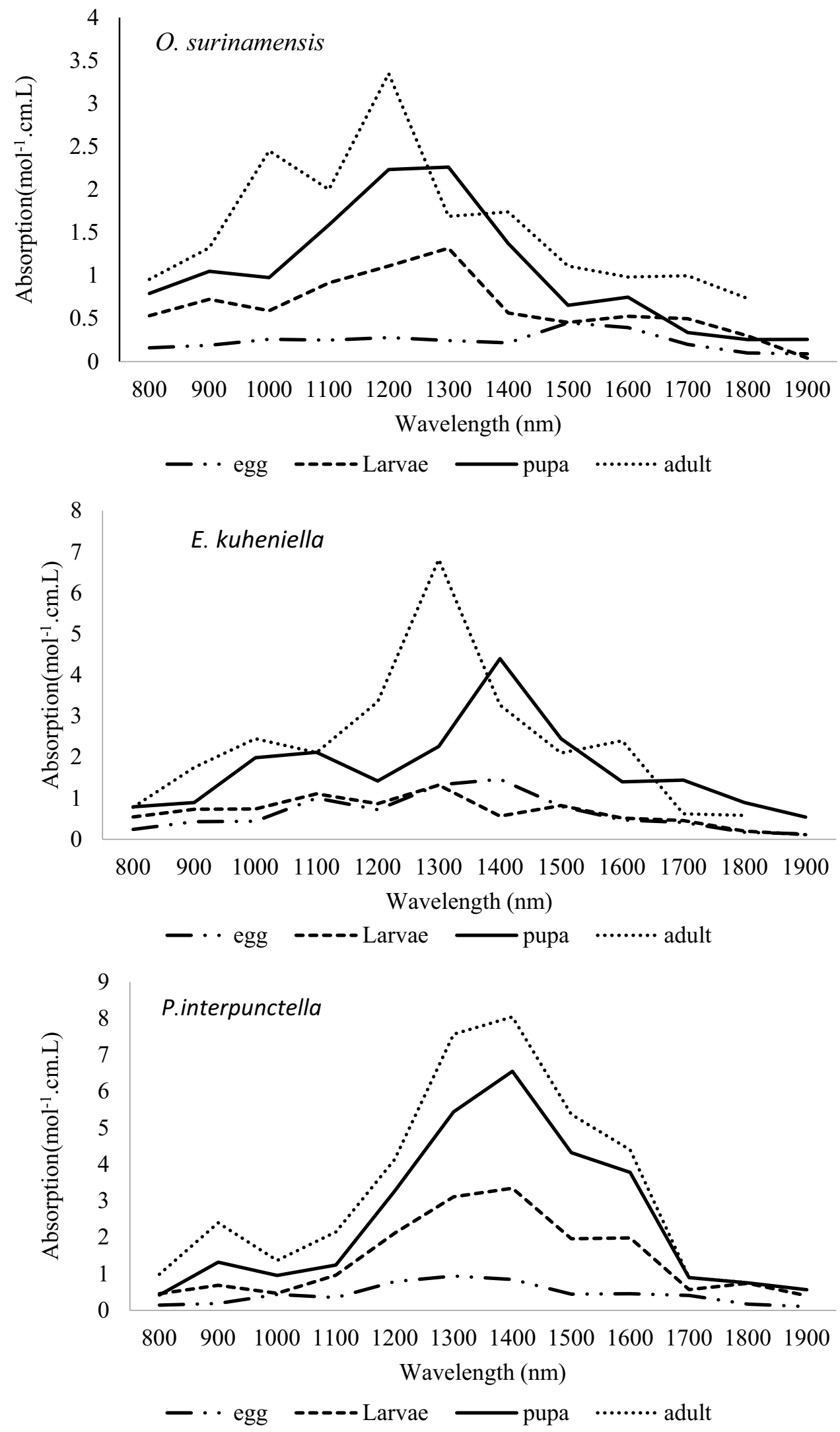
tested insects at different life cycle stages (Fig. 1). Based on the results, the maximum absorptions were between 1100 to $1300 \mathrm{~nm}, 1200$ to $1400 \mathrm{~nm}, 1100$ to $1400 \mathrm{~nm}$ and 1000 to $1400 \mathrm{~nm}$ for $O$. surinamensis, 1100 to $1400 \mathrm{~nm}, 1200$ to $1500 \mathrm{~nm}, 1300$ to $1500 \mathrm{~nm}$, and 1300 to $1600 \mathrm{~nm}$ for E. kuehniella. 1300 to $1500 \mathrm{~nm}, 1200$ to $1600 \mathrm{~nm}, 1100$ to $1600 \mathrm{~nm}$ and 1100 to $1700 \mathrm{~nm}$ for $P$. interpunctella, in the stages of egg, larva, pupa and adults, respectively.

The most fitting wavelength is shown in Fig. 2. The most suitable wavelength is the maximum point of these curves, which shows the maximum absorption for different life cycle stages in the final model.

The most suitable wavelengths were calculated for different life cyclestages and their related densities based on Fig. 2. The results are presented in Table 1.

As shown in Table 1, the wavelengths for the maximum detections for adults of $O$. surinamensis, E. kuehniella and $P$. interpunctella were $1270 \mathrm{~nm}, 1490 \mathrm{~nm}$, and the least for eggs of $O$. surinamensis, E. kuehniella and P. interpunctella was equal to 1210,1320 and $1350 \mathrm{~nm}$, respectively. According to the results, the mean suitable wavelengths for estimating densities at different life cycle stages were 1280, 1335 and $1390 \mathrm{~nm}$ for $O$. surinamensis, E. kuehniella and P. interpunctella, respectively.

\section{Comparison of spectrophotometric absorption of different infections}

There are significant differences between the spectrophotometric absorption for different insect species (MS $=149.12$ and $\mathrm{df}=2$ ), life cycle stages ( $\mathrm{MS}=183.81$ and $\mathrm{df}=3)$, and their interactions ( $\mathrm{MS}=6.86$ and $\mathrm{df}=6)$ at $1 \%$ probability level. The interaction effects of these two factors were compared by Duncan's test at 5\% probability level, due to the aim of estimations, which was determining the species and their life cycle stages (Fig. 3).

According to the results, there was a significant difference between different absorptions and no overlap was observed for all life cycle stages instudied insects. In other words, it was possible to identify insect's species and their life cycle stages by using spectrophotometer.

\section{Calibrating the relationship between different absorptions and population densities}

The linear calibration curves of the relationships between different densities and absorptionsare shown in Fig. 4 for eggs, larva, pupa and adults for all the three species. According to the results,calibration curves showed coefficient above 90 percent. Calibration error for eggs, larva, pupa and adults were equal to 6, 4, 6 and $2 \%$ for $O$. surinamensis, 2, 5, 1 and 8\%, for, E. kuehniella and 10, 8, 7 and $9 \%$, for
P. interpunctella, respectively. Therefore, the high ability of this procedure for estimating the population density of insects at all life cycle stages was shown.

\section{The efficiency and sample size}

The RV and RNP indices were used to compare the sample size and also the efficiency of the spectrophotometric method. The results are shown in Table 2 .

As shown in Table 2, the RV of spectrophotometric method wasless than 10 . Therefore, this method can be used to estimate the population density of all life cycle stages and determining the insects species in the different researches and field work applications. Its RNP was less than 25 in 8 out of 12 cases. So, this method has a comparative benefit in accuracy and also in reducing cost.

\section{Discussion}

The results of this study showed that there was no overlap in the absorptions, between different life cycle stages of all three species in Date, Deiri cultivar. In other words, the spectrophotometric method has the ability to detect the insect's species and their different life cycle stages in the Date, Deiri cultivar. The coefficient was higher than 0.5, which indicates its power for detecting different life cycles stages of studied insects. Therefore, indicates the suitability of maximum absorption wavelength in detection process.

Numerous similar studies have been conducted by other researchers on the maximum absorption wavelength for different storage pests instored agricultural products. For example, 1100,1450 to $1440,1014,1680 \mathrm{~nm}$ for detection of A. advena, O. surinamensis in cereals, $S$. granaries in maize and $R$. domenica in cereals respectively (Chambers and Ridgway 1996). The spectrophotometric method has been used successfully to determine various pests including Oryzaephilus mecator (Fauvel), O. suranamensis, Cryptolestes pusillus (Schönherr), Tribolium confusum (Duval), $T$. castaneum, P. truncatus, Sitophilus zaemais (Motschulsky), Sitophilus granarius (Linnaeus), Ahasverus advena (Waltl) and $R$. dominica (Perez-Mendoza et al. 2003; Burks et al. 2000; Chambers and Ridgway 1996; Chambers et al. 1998, 2001; Dowell et al. 1998).

In this research, the wavelength of $1210 \mathrm{~nm}$ was found to be suitable for detection of adult $O$. surinamensis, which indicated approximately $240 \mathrm{~nm}$ difference with similar research. The cause of the difference may be due to difference in pests'activities surrounding the foods, which caused decrease in the maximum absorption wavelength in 
Fig. 2 Fitting curves of the relationship between wavelength and absorption for different life cycle stages of $O$. surinamensis, E. kuehniella and P. interpunctella in Date (Deiri cultivar)
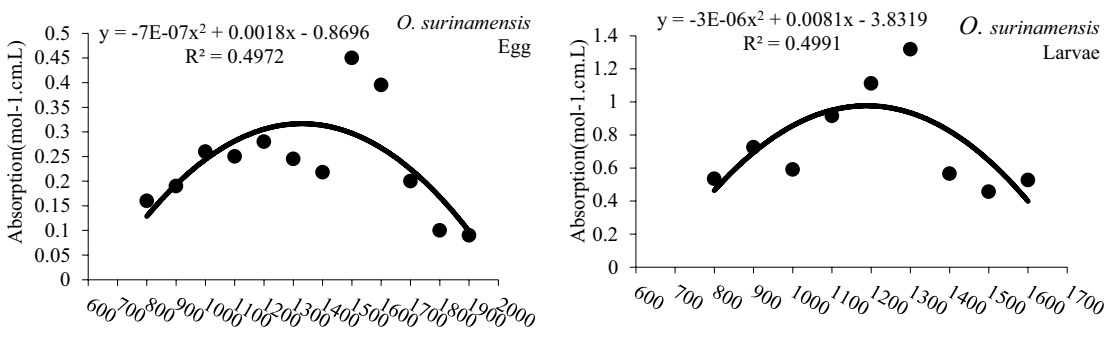
Wavelength $(\mathrm{nm})$
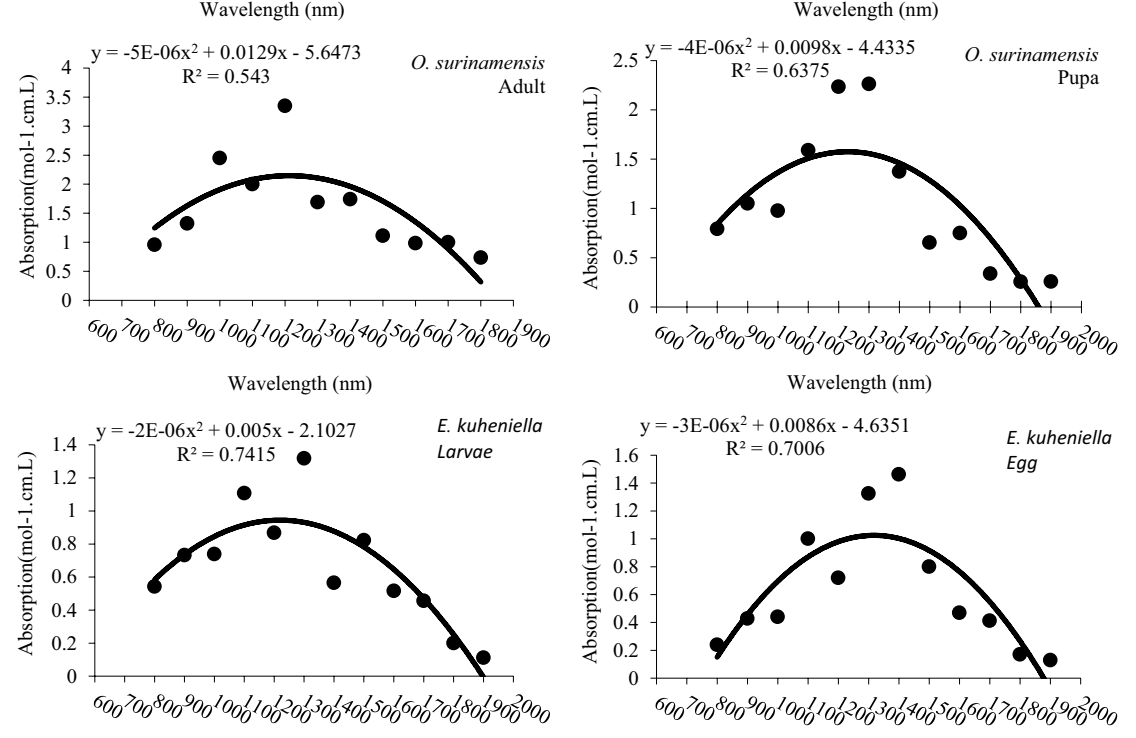
Wavelength (nm)
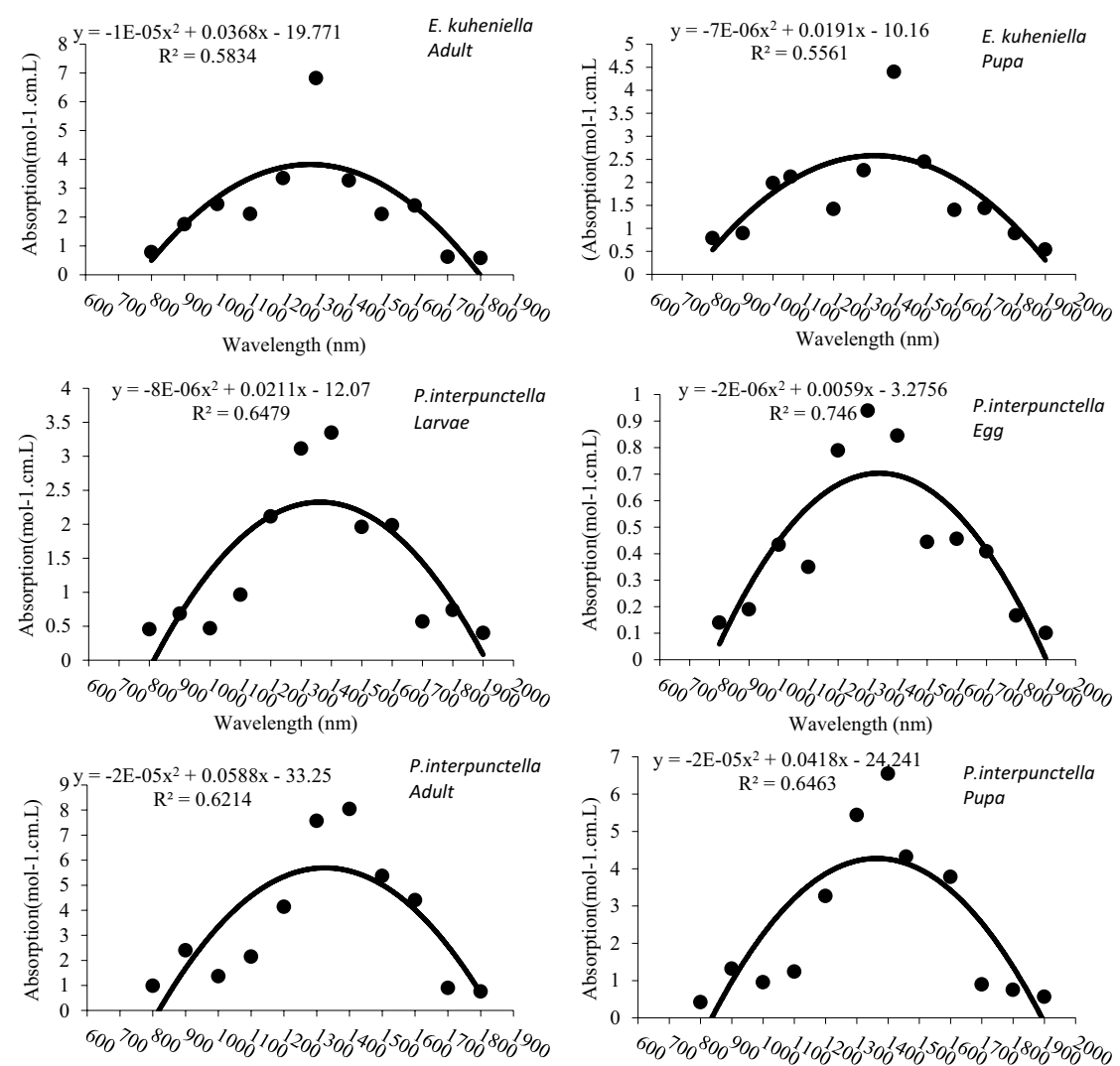

Wavelength (nm)

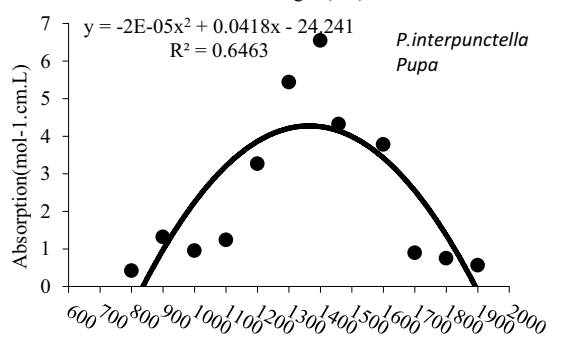

Wavelength (nm) 
Table 1 The most appropriate wavelength for identification of different life cycles tages of $O$. surinamensis, E. kuehniella and P. interpunctella in Date (Deiri cultivar)

\begin{tabular}{lll}
\hline Pests & Life cycle stages & Wavelength (nm) \\
\hline O. surinamensis & Egg & 1210 \\
& Larva & 1230 \\
& Pupa & 1250 \\
& Adult & 1270 \\
E. kuehniella & Egg & 1320 \\
& Larva & 1340 \\
& Pupa & 1380 \\
& Adult & 1390 \\
& Egg & 1350 \\
& Larva & 1400 \\
& Pupa & 1410 \\
& Adult & 1420 \\
\hline
\end{tabular}

the Date (Deiri cultivar). The highest and lowest detection power were reported for adults and eggs in Date (Kabkab cultivar), respectively (Heidary et al. 2014). Whereas, in this research spectrophotometric method had the highest ability to detect eggs and larva in Date (Deiri cultivar).

The spectrophotometric method requires small sample size to obtain sufficient accuracy, so that in most cases the number of insects didn't exceed from three. However, the sample size was increased by increasing the developmental stage. Accordingly, the eggs and adults had the maximum necessary sample size in this method, due to the increasing difference in insects body composition. Because the most wavelengths are absorbed by the chitin in the spectrophotometer wavelength ranges. Although the probability of detection and error were increased by increasing the population density in the samples and the need for repeating the sampling was increased.

Sample mensuration is as important sampling design in the spectrophotometric method. In this method, the population parameters were measured in two stages. In the first step, the absorption was recorded by the spectrophotometer. In the second step, the absorption data was converted to population density by calibration curves. In the first phase, which was the absorption measurement phase, the spectrophotometer operations were done digitally with precision at 0.00001 and the high-quality data could be coded and entered into the calibration curve equation for processing. In this phase, on the base of specialist's knowledge about the spectrophotometric methods, collecting authentic and reliable data is required. Which requires conducting different training courses about spectrophotometer. The population density estimation with using the calibration curve has certain confidence levels. The results of this research showed that the calibration curves were standard. Because the coefficient was above 0.9 in all cases. In other words, the probability of error was less than 10 percent and population parameters estimation was acceptable in the sampling program of $O$. surinamensis, $E$. kuehniella and P. interpunctella in Date (Deiri cultivar).

In this study, sampling accuracy was suitable for all different life cycles tages of $O$. surinamensis, E. kuehniella and $P$. interpunctella in Date (Deiri cultivar) and it was much lower than 10, as the threshold limit. The important point that distinguishes the spectrophotometric method from other methods is its high accuracy in evaluating hidden life cycle stages such as eggs and pupa, which is even more accurate than the obvious stages such as larva and adult. This makes spectrophotometric method ideal for specific cases such as customs and quarantine evaluations.

The RNP indices were higher than the minimum requirement for all life cycle stages of $O$. surinamensis, $E$. kuehniella and P. interpunctella in Date (Deiri cultivar). So, spectrophotometer can be used to evaluate population density of studied insects. More importantly, this method has the highest accuracy and least cost for estimation of hidden life cycle stages of $O$. surinamensis, E. kuehniella and $P$. interpunctella in Date (Deiri cultivar). Therefore, it makes the spectrophotometric method superior to other methods such as PCR and ELISA (Sola 2016).
Fig. 3 Mean comparison of spectrophotometric absorption for different life cycle stages of O. surinamensis, E. kuehniella and P. interpunctella in Date (Deiri cultivar)

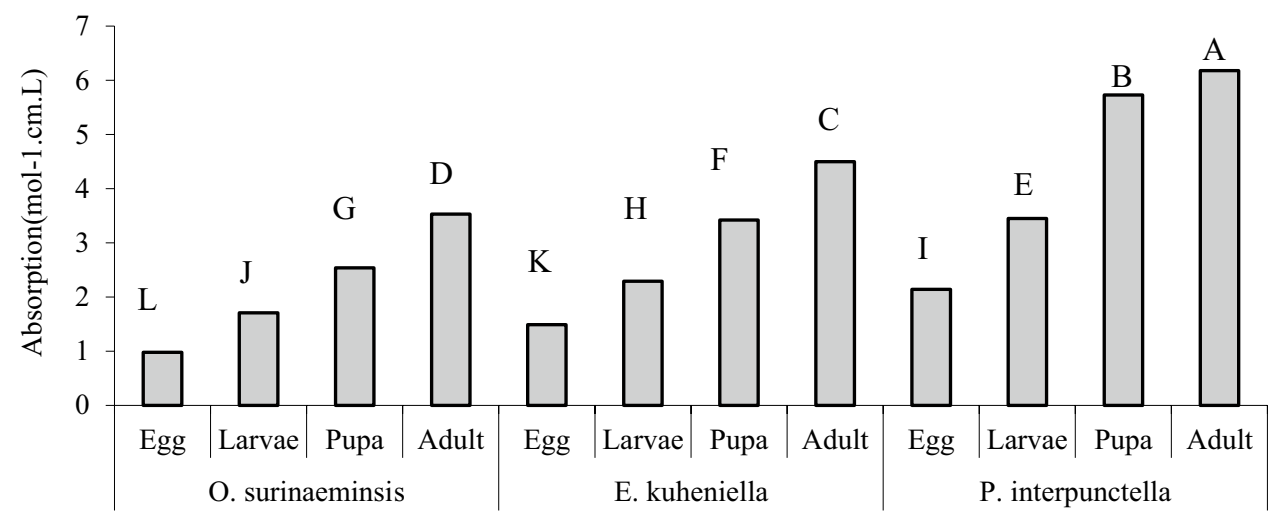


Fig. 4 Fitting curves of the relationship between absorptionand density for life cycle stages of O. surinamensis, E. kuehniella and $P$. interpunctellain Date (Deiri cultivar)
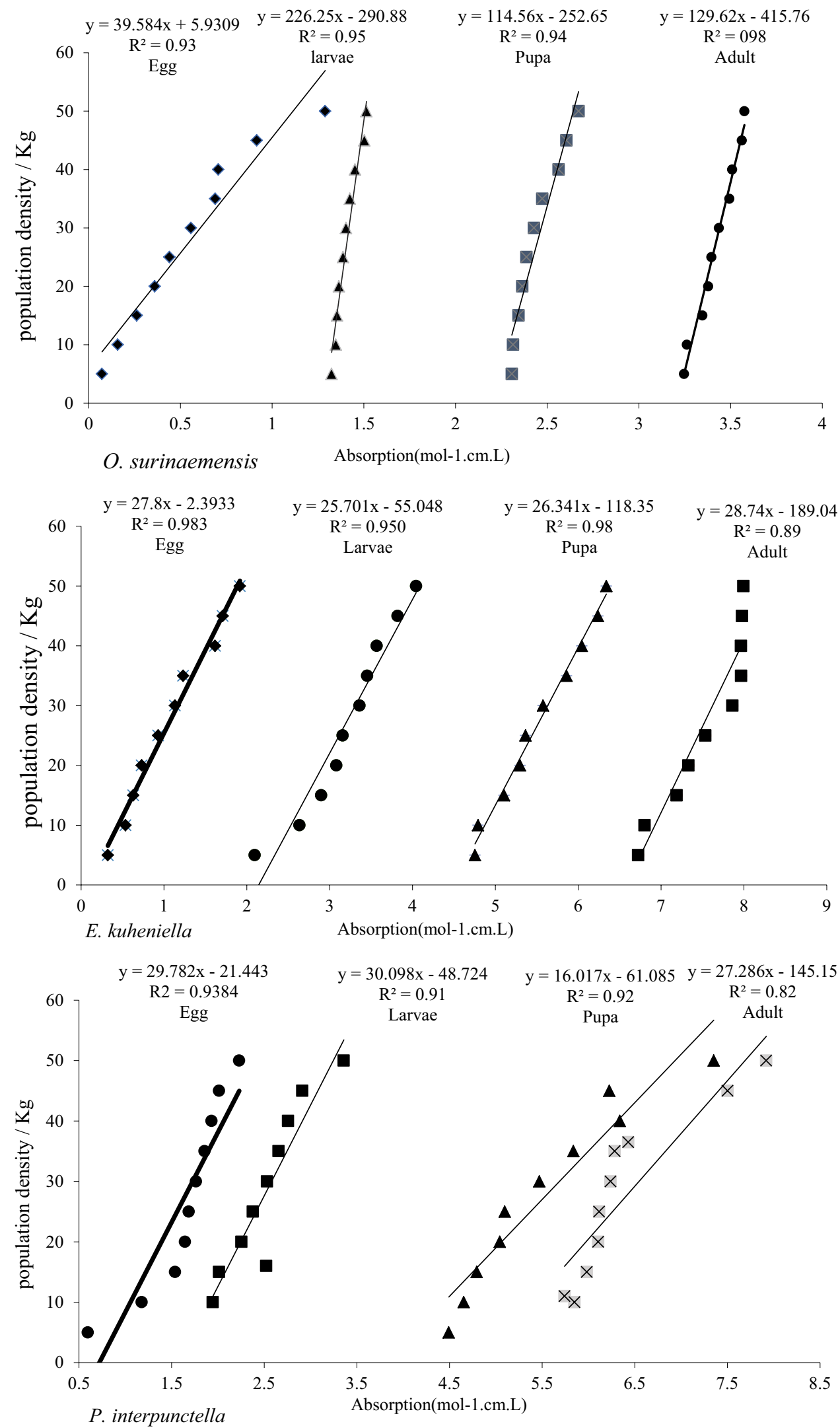
Table 2 The sample size and spectrophotometric efficiency for estimating the population density of different life cycle stages of $O$. surinamensis, $E$. kuehniella and P. interpunctella in Date (Deiri cultivar)

\begin{tabular}{lllllllll}
\hline Pests & Life cycle stages & $\mathrm{S}^{2}$ & $\bar{x}$ & $s \bar{x}$ & $\mathrm{C}$ & $\mathrm{RV}$ & $\mathrm{RNP}$ & Samples size \\
\hline O. surinamensis & Egg & 1.54 & 31.91 & 0.44 & 2 & 1.39 & 35.95 & 1 \\
& Larva & 4.81 & 57.58 & 1.39 & 2 & 2.41 & 20.73 & 2 \\
& Pupa & 0.93 & 9.25 & 0.27 & 2 & 2.91 & 17.19 & 2 \\
& Adult & 1.06 & 9.83 & 0.31 & 2 & 3.12 & 16.06 & 2 \\
E. kuehniella & Egg & 4.02 & 72.75 & 1.16 & 2 & 1.59 & 31.32 & 1 \\
& Larva & 2.08 & 36.92 & 0.6 & 2 & 1.63 & 30.69 & 1 \\
& Pupa & 1.79 & 11.17 & 0.52 & 2 & 4.62 & 10.82 & 3 \\
& Adult & 1.15 & 7.67 & 0.32 & 2 & 4.34 & 11.53 & 3 \\
& Egg & 2.69 & 43.83 & 0.78 & 2 & 1.78 & 28.15 & 1 \\
& Larva & 2.64 & 23.5 & 0.76 & 2 & 3.24 & 15.42 & 2 \\
& Pupa & 1.47 & 16.25 & 0.43 & 2 & 2.62 & 19.05 & 2 \\
& Adult & 0.63 & 8.08 & 0.93 & 2 & 2.24 & 22.27 & 2 \\
\hline
\end{tabular}

Similar studies have been conducted to estimate the population of O. surinamensis and E. kuehniella in dates (Sayercultivar) by using spectrophotometric method. In all studies, RV and RNP were less than 10 and greater than 25 in all cases, which is similar to our findings (Latifian et al. 2013; Latifian and Rad 2015). The results of this study showed that spectrophotometric method can be used for detecting the population density of hidden life cycle stages (large larva, pupa and adults) of O. surinamensis, E. kuehniella and P. interpunctella in Date (Deiri cultivar). Further researches are needed to investigate the effects of Date quality and the differences of storage pest populations in other regions, to determine their impact on the accuracy of spectrophotometric method in different conditions.

\section{Declarations}

Competing interest All authors declare that there are none interest to declare. Also by this declaration all authors confirm that this manuscript has not been published elsewhere and it is not under considerationby another journal. All authors have approved the manuscript and agree with its submission to International Journal of Tropical Insect Science.

Open Access This article is licensed under a Creative Commons Attribution 4.0 International License, which permits use, sharing, adaptation, distribution and reproduction in any medium or format, as long as you give appropriate credit to the original author(s) and the source, provide a link to the Creative Commons licence, and indicate if changes were made. The images or other third party material in this article are included in the article's Creative Commons licence, unless indicated otherwise in a credit line to the material. If material is not included in the article's Creative Commons licence and your intended use is not permitted by statutory regulation or exceeds the permitted use, you will need to obtain permission directly from the copyright holder. To view a copy of this licence, visit http://creativecommons.org/licenses/by/4.0/.

\section{References}

Al-Dosari SA, Suhaibanui MA, Ali AG (2002) Susceptibility of some dry date palm varieties to infestation by Oryzaephilus surinamensis L., Coleoptera: Silvanidae in relation to their chemical composition. Assiut Journal of Agricultural Sciences, Assiut University. KSU, P.O. box 2460, Riyadh 11451, Saudi Arabia

Arbogast RT, Mankin RW (1999) The utility of spatial analysis in management of storage pests. In "Stored Product Protection: Proceedings of the 7th International Working Conference on Stored-product Protection', (Xuxun J, Quan L, Yongsheng L, Xianchang T, Lianghua G, eds), pp 1519-1527. Sichuan Publishing House of Science and Technology, Chengdu, China

Bowditch TG, Madden JL (1996) Spatial and temporal distribution of Ephestia cautella (Walker) (Lepidoptera: Pyralidae) in a confectionary factory: Causal factors and management implications. J Stored Prod Res 32:123-130. https://doi.org/10.1016/0022474X(96)00008-2

Burks CS, Dowell FE, Xie F (2000) Measuring fig quality using near-infrared spectroscopy. J Stored Prod Res 36:289-296. https://doi.org/10.1016/s0022-474x(99)00050-8

Chambers J, Ridgway C (1996) Rapid detection of contaminants in cereals. In: "Near Infrared Spectroscopy. The Future Waves" (A.M.C. Davies and P. Williams, eds), pp 484-489. NIR Publications, Chichester, UK

Chambers J, Ridgway C, Davies ER, Mason DR, Bateman MW (1998) Rapid automated detection of insects and certain other contaminants in cereals. Home-Grown Cereals Authority Project report no. 152. London, UK

Chambers J, Ridgway C, Davies ER (2001) Design of an integrated machine vision system capable of detecting hidden infestation in wheat gains. Home-Grown Cereals Authority Project report no. 262. London, UK

Dowell FE, Throne JE, Wang D, Baker JE (1998) Automated nondestructive detection of internal insect infestation of wheat kernels by using near-infrared reflectance spectroscopy. J Econ Entomol 91:899-904

Dudhe PB, Chavare PD, Shelke PS (2017) Spectrophotometric determination of febuxostat from bulk and tablet dosage form by area under curve method. Int J ChemTech Res 10(6):183-189 
Gorham JR (1991) Insect and mite pests in food. An illustrated key. Vol. 1 and 2. US Department of Agriculture, Agriculture Handbook Washington, DC, USA. p 495

Heidary N, Latifian M, Fallahzaseh M (2014) The spectrophotometry method to evaluating in the infestation level of developmental stages of Ephestia kuehniella in type date palm Kabkab. Plant Protection Journal 6(1):17-28

Huang J, Dong M, Lu S, Li W, Lu J, Liu C, Yoo JH (2018) Estimation of the mechanical properties of steel via LIBS combined with canonical correlation analysis (CCA) and support vector regression (SVR). J Anal At Spectrom 33(5):720-729. https://doi.org/ 10.1039/C8JA00030A

Jinendra B, Tamaki K, Kuroki S, Vassileva M, Yoshida S, Tsenkova R (2010) Near infrared spectroscopy and aquaphotomics: Novel approach for rapid in vivo diagnosis of virus infected soybean. Biochem Biophys Res Commun 397:685-690. https://doi.org/10. 1016/j.bbrc.2010.06.007

Latifian M, Rad B, Ghamari M (2013) Determination the population density of different development stages of Mediterranean meal moth Ephestia kuehniella Zell. in Date fruit Sayer cultivar based on spectrophotometry. J Plant Protec 27(4):491-510. (in Persian with English summary)

Latifian M, Rad B (2015) Determination of the population densities of different development stages of Sawtoothed beetle Oryzaephilus surinamensis L. in Date fruitSayer cultivar busing spectrophotometry method. Journal of Entomological Research 6(4):353-365. (in Persian with English summary)

Lu J, Zhou M, Gao Y, Jiang H (2017) Using hyperspectral imaging to discriminate yellow leaf curl disease in tomato leaves. Precis Agric 1-16. https://doi.org/10.1007/s11119-017-9524-7

Mahlein AK (2016) Plant disease detection by imaging sensors parallels and specific demand for precision agriculture and plant phenotyping. Plant Dis 100:241-251. https://doi.org/10.1094/ PDIS-03-15-0340-FE

Mallah NA, Sahhito HA, Kousar T, Kubar WA, Shah ZH (2016) Susceptibility of different varieties of stored Date fruits infested by saw tooth grain beetle, Oryzaephilus surinamensis (L., 1758) under laboratory conditions. Journal of Entomology and Zoology Studies 4(6):438-443

Morrison WR, Bruce A, Wilkins RV, Albin CE (2019) Influences of stored product insect movements on integrated pest management decisions. Insects 77(10):1-20
Naidu RA, Perry EM, Pierce FJ, Mekuria T (2009) The potential of spectral reflectance technique for detecting Grapevine leafrollassociated virus-3 in two red-berried wine grape cultivars. Comput Electron Agric 66:38-45. https://doi.org/10.1016/j.compag. 2008.11.007

Perez-Mendoza J, Throne JE, Dowell FE, Baker JE (2003) Detection of insect fragments in wheat flour by near-infrared spectroscopy. J Stored Prod Res 39:305-312. https://doi.org/10.1016/S0022474X(02)00021-8

Ridgway C, Davies R, Chambers J (2001) Imaging for the high-speed detection of pest insects and other contaminants in cereal grain in transit. Paper presented at the 2001 ASAE Annual International Meeting, California, July 30-Aug. 1, 2001

Sankaran S, Mishra A, Ehsani R, Davis C (2010) A review of advanced techniques for detecting plant diseases. Comput Electron Agric 72:1-13. https://doi.org/10.1016/j.compag.2010.02.007

Sola M (2016) Detection, identification, and quantification of insect infestation in stored products using PCR approaches. https://doi. org/10.1603/ICE.2016.111999

Throne JE, Dowell FE, Perez-Mendoza J, Perez-Mendoza JE (2003) Entomological applications of near-infrared spectroscopy. In "Proceedings of the 8th International Working Conference on Stored-product Protection' (P.F. Credland, D.M. Armitage, C.H. Bell, P.M. Cogan, and E. Highley, eds), pp 131-134. CAB International, Wallingford, UK

Wilkin DR, Cowe IA, Thind BB, McNicol JW, Cuthbertson DC (1986) The etection and measurement of mite infestation in animal feed using near infra-red reflectance. J Agric Sci 107:439-448. https:// doi.org/10.1017/S0021859600087244

Wilkin DR, Fleurat-Lessard F (1991) The detection of insects in grain using conventional sampling spears. In "Proceedings of the 5th International Working Conference on Stored product Protection", (Fleurat-Lessard F, Ducom P, eds), pp 1445-1453. Bordeaux, France

Williams P, Norris K (2001) Near-infrared Technology in the Agricultural and Food Industries. American Association of Cereal Chemists, St. Paul, MN

Zayas IY, Flinn PW (1998) Detection of insects in bulk wheat samples with machine vision. Trans ASAE 41:883-888 